\title{
Operation and Predicativity: Lorenzen's Approach to Arithmetic
}

\author{
Gerhard Heinzmann
}

\begin{abstract}
In this article we give an overview, from a philosophical point of view, of Lorenzen's construction of the natural and the real numbers. Particular emphasis is placed on Lorenzen's classification in the tradition of predicative approaches that stretches from Poincaré to Feferman.
\end{abstract}

\section{Introduction}

German philosophy of science (Wissenschaftstheorie) in the second half of the 2oth century was dominated by two outstanding personalities: Paul Lorenzen and Wolfgang Stegmüller. Both are witnesses to a common yet very differently interpreted heritage of logical empiricism: Stegmüller situates the project of a formal semantics in the tradition following Carnap; Lorenzen "takes over" only the insight to understand philosophy of science as the theory of the language of science, and develops a constructive philosophy characterized by a phenomenological-operative approach to mathematics (cf. Gethmann 1991 and Thiel 2014): "Constructive philosophy is phenomenology after the linguistic turn" (Gethmann and Siegwart 1994, 228).

In 1962, Lorenzen joined his friend Wilhelm Kamlah at the University of Erlangen, and together they wrote the textbook Logische Propädeutik: Eine Vorschule des vernünftigen Denkens ("Logical propaedeutic: A pre-school of reasonable thinking"; 1967), which became a kind of manifesto of the "Erlangen School" (cf. Mittelstraß 2008; 2016). The first members of this school were Kuno Lorenz, Jürgen Mittelstraß, Christian Thiel, Peter Janich, Hans-Jürgen Schneider, Friedrich Kambartel and Carl Friedrich Gethmann.

Gerhard Heinzmann

Archives Henri-Poincaré (UMR 7117), Université de Lorraine/Université de Strasbourg, CNRS-PReST, F-5400o Nancy, France, e-mail: gerhard.heinzmann@univ-lorraine.fr 
The monumental Enzyklopädie Philosophie und Wissenschaftstheorie, published by Mittelstraß, is an application of the "Erlangen Program", originally developed in logic and mathematics, to all areas of philosophy and philosophy of science.

The operative mathematics of Paul Lorenzen is an attempt to understand and "rescue" the results of classical mathematics by using a predicative approach. ${ }^{1}$ Thanks to the distinction between "definite" and "indefinite" concept formation, the classical results - except those requiring large cardinals - can be conserved without substantial modification (see Lorenzen 1965, 4).

Shortly before his death, Hermann Weyl praised Lorenzen's famous Einführung in die operative Logik und Mathematik ("Introduction to operative logic and mathematics"; 1955a), and in turn Lorenzen dedicated to Weyl his work Differential und Integral (Lorenzen 1965). Weyl $(1985,38)$ not only affirmed that his "heart draws onto the side of constructivism", but he also noted that Lorenzen's book 1955a is a big step forward and the best way to understand mathematics:

Today it seems to me that Paul Lorenzen's operative approach opens the most viable way out of the difficulties. ... The operations of the formal calculus are here intertwined in a fruitful and unconstrained way with substantive considerations about their products; Gödel's discovery loses everything that disturbs us. (Weyl 1968, 180)

Lorenzen was one of the first to explicitly develop predicative analysis as an extension of Weyl's 1918 approach. In fact, Weyl introduced a narrower iteration method (Weyl 1918, 21, 23), according to which he refrained from quantifying over set variables in the definition of sets of natural numbers, limiting the range of variability to natural numbers, and only accepted "objects" introduced by definition, so that he obtained as results predicative sets modulo natural numbers. From this it follows that the definition of a supremum (or "least upper bound", l.u.b.) in the real numbers $\mathbb{R}$ is circular (not predicative) and the completeness assertion for $\mathbb{R}$, that every non-empty but bounded set of real numbers has an l.u.b., is not valid, and therefore the theory revisionist. ${ }^{2}$ To get the completeness of $\mathbb{R}$ in Weyl's approach, one must define the bounds not in terms of sets but in terms of sequences of real numbers. ${ }^{3}$

The idea of the general approach of Lorenzen's operative mathematics is far less known than the dialogical logic developed by Lorenzen and Kuno

\footnotetext{
${ }^{1}$ A definition is called "predicative" if, in the definiens, the definiendum does not occur and no reference is made to it; otherwise it is impredicative.

${ }^{2}$ In other words, it deviates from a majority practice.

3 "We say that a sequence $S_{n}$ of real numbers is given if we have a set $T$ such that for each $n, x \in S_{n} \leftrightarrow\langle x, n\rangle \in T$. Then the l.u.b. of the $S_{n}$, which we identified earlier with $\bigcup S_{n}[n \in \omega]$, is defined arithmetically in terms of $T$ by $\forall y(\langle x, y\rangle \in T)$ " (Feferman 1964, 7).
} 
Lorenz. ${ }^{4}$ Not only influenced by Weyl, but also by Hugo Dingler (1913; 1931) ${ }^{5}$ and Haskell B. Curry (1951), ${ }^{6}$ Lorenzen devoted himself primarily to the reconstruction of analysis, while the application to geometry found a much lesser impact.7

\section{The main philosophical considerations}

The starting point of Lorenzen's philosophical idea can be found in his introduction to Differential und Integral: The axiomatized systems of analysis formulated in set theory, according to which "every assertion of classical analysis ... can be transformed into the assertion of the derivability of a certain formula in a certain calculus, has the ... disadvantage that the choice of the calculus can only be pragmatically justified". That this pragmatic justification is "the only possibility of justification", if considered at all, is "an unfounded assertion". On the other hand, according to Lorenzen, "neither the metaphysics of pragmatism" nor Platonist speculations on mathematical objects are necessary for the foundation of classical analysis (Lorenzen 1965, $1-2)$.

As a positive solution, Lorenzen proposes an operative-constructive approach to mathematics that includes the entire justified heritage of mathematics. In a substantial deviation from Hilbert's contentual (finitary) standpoint, justification is intended to fulfill two very large criteria:

1. Constructive Mathematics has to be shown as a possible human activity.

2. Constructive Mathematics has to be shown as a good possibility, at least as a better possibility than its rivals, i.e. set-theoretical mathematics in naive or axiomatic forms. (Lorenzen 1968, 133)

According to Lorenzen, the first perspective of justification concerns an epistemological problem, the second a moral problem in the sense of an evaluation.

The starting point of the epistemological justification is a consensus on the functioning of ordinary (and therefore imprecise) language on a practical level. The "practical" turn here refers to a spontaneous understanding (Vorverständnis) of science based on a technical and political practice. ${ }^{8}$

On this common practical basis, Lorenzen proposes gradually to develop rules that lead first to "concrete mathematics" and finally to "ab-

4 Cf. Lorenzen and Lorenz 1978; Keiff 2011; Fontaine and Redmond 2008; Rahman, McConaughey, Klev, and Clerbout 2018.

5 Cf. Schlaudt 2014 for the reception of Hugo Dingler by the Erlangen School.

${ }^{6}$ Cf. Lorenzen 1955a, 3-4, 6; 1968, 136.

7 Note, however, Lorenzen (1961; 1987, 191-203), Janich (1989) and Inhetveen (1983), who, following ideas by Hugo Dingler, try to define the notions of plane, orthogonality and parallelism with the help of the concept of homogeneity.

${ }^{8}$ Cf. Lorenzen 1994, which is the publication of a lecture held in 1989 in Göttingen under the title "Die praktizistische Wende der Wissenschaftstheorie". 
stract mathematics". "Abstract mathematics" differs from "concrete" or operative mathematics in that the former additionally introduces the axiomatic method - of course without a justification (Lorenzen 1955a, 8). Lorenzen has in mind a process of abstraction which avoids the limitations of nominalists (such as Goodman), who reject "abstract" objects and instead confine themselves to "concrete" individuals, as well as the limitations of skeptical finitists, who only allow restricted sets as abstract objects, but without going as far as the Cantorians, who allow indefinitely many infinities of different cardinality. In short, he defends the middle position of the golden mean (cf. Lorenzen 1968, 136, 140).

In the "non-axiomatic", that is to say, concrete, operative mathematics (Lorenzen 1955a, 195), any statement, for example, of "theoretical" arithmetic, can be interpreted as a statement about the methods or rules of "practical" arithmetic. This latter is a syntactic calculus for constructing, according to certain rules or schemes, symbols called "figures", for example, the number signs "|", "||", "|||", ..., where "..." means that an indefinite, but finite, number of number signs follows. Theoretical statements are not axiomatic formalizations but rather "specifications" of the practical calculation (Lorenzen 1955a, 196).

An evaluation becomes necessary in relation to axiomatic theories for which we have neither a constructive model nor a constructive proof of consistency. Examples are ZF or Peano arithmetic, supplemented by
axioms for the real numbers, $x, y, \ldots$, especially the classical completeness axiom ... In this completeness axiom we could use sentence-forms $A(x)$ of the theory instead of sets. The point is that the sentence-form $A(x)$ with one free variable $x$ for reals may contain bound real variables too. If we use a restricted completeness axiom, the restriction being that $A(x)$ may contain no bound real variables, we get a theory $\mathbb{R}_{0}$ for which a constructive model easily may be found. (Lorenzen $1968,138)$

If we denote the theory of real numbers with the unrestricted axiom of completeness by $\mathbb{R}$, the question arises: Which of the theories, $\mathbb{R}$ or the revisionist theory $\mathbb{R}_{0}$, is better justified? As long as there is no physical result on the basis of $\mathbb{R}$ that is inaccessible on the basis of $\mathbb{R}_{0}$, Lorenzen argues for $\mathbb{R}_{0}$; for the hierarchy of transfinite cardinals does not seem to him to be more important to mathematics than the hierarchy of medieval angels for modern theology (cf. ibid.).

Generally speaking, Lorenzen's "philosophical conditioning of mathematics" consists of four points, which are controversially discussed in the philosophy of mathematics, namely,

1. the rejection of the actual infinite,

2. the avoidance of the general concept of power set,

3. the rejection of impredicative concept formation,

4. the restriction to an operational-constructive method. 
Let us now turn to the more specific form of this constructive "mild" revisionism. ${ }^{9}$ First of all, by using the example of practical arithmetic, we should take into account that the term "operative" does not mean a methodical requirement but rather refers to the object of theoretical arithmetic: the operations as actions and rules of practical arithmetic. Lorenzen (1955a, 3-5) generally considers the objects of operative mathematics to consist in the calculations in this sense.

\section{The construction of the natural and the real numbers}

Of course, Lorenzen does not begin his reconstruction of mathematics with an axiom system for real numbers or sets, but with the construction of natural numbers - by Weyl, they were presupposed - and then moves on to the real numbers and the formation of sets of them. This way of thinking is obviously compatible with the axiomatic approach in its non-fundamentalist interpretation: ${ }^{10}$

After the objects of analysis are constructed, the interrelations between the proofs of the propositions about them can best be clarified by considering the objects with some relationships defined between them as models of suitable structures (field, lattice, topological space, etc.). (Lorenzen 1965, 2)

In his Differential und Integral, Lorenzen gives an operational version not only of natural and real numbers, but also of functions and differential geometry. Here, we limit ourselves to a sketch of the construction up to the real numbers.

The beginning of elementary arithmetic is given by a calculus for the creation of figures, here: number signs $|,\|\||,, \ldots$ Starting with

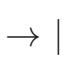

and the rule

$$
m \rightarrow m \mid, \quad \text { (potential infinite) }
$$

one adds rules for identity, addition and multiplication etc.:

$$
\begin{gathered}
\rightarrow|=|, \\
m=n \rightarrow m|=n|,
\end{gathered}
$$

\footnotetext{
9 I call a position "mildly" revisionist if it does not accept the majority practice but nevertheless seeks to understand and justify the theorems and concepts of mathematics accepted by the majority, by taking into account philosophical criteria considered as in a logical sense prior to science.

${ }^{10}$ In this context, Lorenzen rightly refers to the non-Hilbertian use of axiomatic by Bourbaki (cf. Heinzmann and Petitot 2020).
} 


$$
\begin{aligned}
& \rightarrow m \oplus|=m|, \\
& \rightarrow m \oplus n|=(m \oplus n)|, \\
& \rightarrow \mid \otimes n=n, \\
& \rightarrow m \mid \otimes n=(m \otimes n) \oplus n .
\end{aligned}
$$

Here, $m$ and $n$ are variables, more precisely "Eigenvariablen", i.e., variables for substitution instances that are exclusively number signs already generated by the calculus. The symbols " $\oplus$ " and " $\otimes$ " are signs for addition and multiplication, respectively, and " $\rightarrow$ " serves as a "message sign" (Mitteilungszeichen) for operations, for example, It is allowed to set "|"; or, If one has " $n$ ", one can go to " $n \mid$ ". While rules are not statements, the statements about the rules are statements of finite theoretical arithmetic; such a statement says, for example, that if the rules lead to $k \otimes m=n$, then they always produce $m \otimes k=n$. The calculus of practical arithmetic, on the other hand, teaches us that

$$
k \otimes m=n \rightarrow m \otimes k=n
$$

is wrong. In this way, Lorenzen comes to a result which is reminiscent of Poincaré in the sense that, in contrast to non-Euclidean geometry, one cannot introduce a non-Peano arithmetic:

In theoretical arithmetic, there is a method of refuting arbitrary "axioms" on the basis of practical arithmetic; just this is the difference from geometry. (Lorenzen 1958, 242-243; cf. Lorenzen 1955b, 129)

The requirement to accept only "definite" statements is a methodological boundary for that part of mathematics which can be regarded as "stable" or "safe". For example, the statement " $x$ is derivable in calculus $K$ " ( 1 ) is definite, since it is decidable on the basis of a "schematic execution of operations with figures" whether (1) is deducible or not. The negation of this

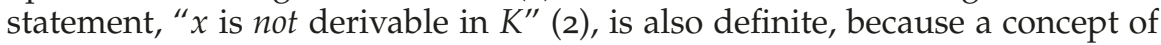
refutation is fixed: the refutation of (2) is given by a proof of (1) (Lorenzen 1955a, 5). Since definite statements can again occur in concepts of proof or refutation, Lorenzen formulates the inductive definition of "definite" as follows:

(1) Any proposition decidable by schematic operations is called "definite".

(2) If a definite proof or refutation concept is defined for a proposition, then the proposition itself is also definite, more precisely proof-definite or refutation-definite. (Lorenzen 1955a, 5-6)

While impredicative concept formation is indefinite and therefore excluded from operative mathematics (Lorenzen 1955a, 6), quantifiers are permissible, provided that the formulas in the quantification domain are definite. If $A(x)$ is definite, then in order to refute $\forall x A(x)$ it is sufficient to refute some formula $A\left(x_{0}\right)$; and in order to prove $\exists x A(x)$ it is sufficient to prove $A\left(x_{0}\right)$.

Lorenzen shows that the five well-known Peano axioms, together with the definitions of addition, multiplication, and exponentiation, can be construed as definite with the help of the construction rules for numerical signs and 
statements about them obtained by means of elementary logical reasoning without the tertium non datur (Lorenzen 1955a, Part 1; cf. Schroeder-Heister 2008).

It should be emphasized that the induction principle is a meta-rule of the form

$$
A(\mid) ;(A(m) \rightarrow A(m \mid)) \rightarrow \forall n A(n)
$$

that constitutes an operative interpretation of the classical induction principle. In fact, the variability range of the universal quantifier in the conclusion is definite: it consists exclusively of numerical signs constructed according to the rules, and all numerical signs are the results of such constructions (Lorenzen 1950, 163; 1965, 7-9; 1955a, 28, 134 sq.). One can see that the revisionism of operative mathematics first becomes apparent in abstract mathematics: the operative system of numerical signs indeed defines a monomorphic structure, i.e., all of its models are isomorphic (cf. Lorenzen 1955a, 136).

For natural and rational numbers the difference between a constructive and an axiomatic approach is only a difference "in the way of talking about arithmetic, not within arithmetic itself" (Lorenzen 1965, 3). The "problematic" step of the operative construction of concrete mathematics is the domain of real numbers, since those are introduced into modern mathematics through a "combination of arithmetic with set theory", which obviously is not definite. Now Lorenzen defines an operative theory of sets, according to which every infinite set is countable. It is foreseeable that this difference has a consequence for the construction of real numbers (cf. Lorenzen 1965, 194-195).

In 1955, Lorenzen constructed real numbers by introducing language levels (Sprachschichten) that are reminiscent of Weyl and Otto Hölder: ${ }^{11}$ The construction of language levels starts with calculus figures, called "objects". By forming definition schemes for these, one obtains functions (addition, multiplication, subtraction, division) and relations between them (identity, less-than). The resulting propositions constitute the objects of the next level, composable by means of logical particles. In 1965, by contrast, Lorenzen uses as his starting point the operative calculus, enriched with logical particles, and his distinction between definite and indefinite formations, and obtains the rational and the real numbers through a process of predicative abstraction. The difficulty that arises in both cases, with or without language levels, is to define the new class of objects that should be the real numbers. In fact, the set of all definite sets of natural numbers, i.e., the power set of $\mathbb{N}$, is not itself definite. There are, however, sets of sets that are definite, such as, for example, the infinite set which has as its elements

the set of all natural numbers [Grundzahlen],

${ }^{11}$ Lorenzen (1955a, 165) himself refers to the "mathematical process" which Weyl describes in 1918, and Oskar Becker (1956/57, 452, note 4), in his discussion of Lorenzen 1955a, calls attention to the fact that related thoughts exist in Hölder 1924. 
the set of all squares of natural numbers,

the set of all cubes of natural numbers,

(Lorenzen 1965, 39 sq.; 1955a, 165 sq.)

How, under these conditions, should one define a real number? Lorenzen goes the classical way and expands the rational numbers such that "all" Cauchy sequences converge. Of course, the Cauchy sequences of rational numbers are not definite sets. Lorenzen must therefore limit himself to the introduction of an indefinite extension procedure, which leads to their limits only for certain definite sequences, but which can always be extended to other definite sequences. The limits are obtained with respect to an equivalence relation between Cauchy sequences: let $r \sim s$ iff the sequence " $r-s$ " with the elements $r_{1}-s_{1}, r_{2}-s_{2}, \ldots$ is a null sequence. One then shows that $r \sim s$ is an equivalence relation and confines oneself in one's statements about Cauchy sequences to those which are invariant modulo " $\sim$ ". Lorenzen calls the abstract objects defined by such invariants "real numbers" (cf. Lorenzen 1965, 54 sq.).

Under the classical approach, the field of real numbers is complete, i.e., every Cauchy sequence of reals which is monotone and bounded converges to a real number. What on the standard approach is called the set of all real numbers is not definite, i.e., it is a "class". It is therefore not surprising that it is provable that every definite set of real numbers is incomplete, i.e., that in every definite set of real numbers there are Cauchy sequences which have no limit in that set.

In fact, the operative construction of the real numbers implies that, for every definite set of real numbers, one can find a bijection into the natural numbers, i.e., each definite set is countable and therefore representable as the elements of a sequence $\zeta_{1}, \zeta_{2}, \zeta_{3}, \ldots$ Lorenzen then shows that a series of real numbers containing all rational numbers in an interval is dense, and that density implies incompleteness.

Therefore, in contrast to classical axiomatics, the operative real numbers do not constitute an ordered and complete Archimedean field (cf. Lorenzen 1965, 61 sqq.). However, the indefinite field of real numbers contains (up to isomorphism) all ordered Archimedean fields and is in this sense the largest ordered Archimedean field. In other words, we now understand the completeness of the indefinite real numbers (ibid., p. 65).

\section{A short outlook on predicative mathematics}

The idea of predicative mathematics as a justified part of mathematics was further developed, with explicit reference to Lorenzen, by Hao Wang:

The Poincaré-Russell notion of predicativity seems to deserve renewed study in view of recent works by Lorenzen and others which appear to give hope of a 
predicative basis for ordinary mathematics. (Wang 1959, 216)

Wang's idea was to start from a multi-leveled constructive set theory and to ask whether one can then give a more accurate characterization of predicativity, "as sharp and acceptable an explication for predicativeness as recursiveness is for the intuitive concept of effective computability" (Wang 1964, 578).

In his introduction to the paper "Realism and the Debate on Impredicativity, 1917-1944" (2002), Charles Parsons echoes Wang's remarks with respect to further developments in a "classical" view of predicativity by Solomon Feferman and Kurt Schütte:

Although in the 1950's Paul Lorenzen and Hao Wang had undertaken to reconstruct mathematics in such a way that impredicativity would be avoided, insistence on this (to which even Wang did not subscribe) was very much a minority view, and Feferman in particular sought principally to analyze what predicativity is, with the understanding that some aspects of this enterprise would require impredicative methods. (Parsons 2002, 372)

An interesting criticism of the predicative conception of the real numbers comes from Paul Bernays. He finds it unconvincing that Lorenzen confines himself to operative intuition and neglects the geometrical aspects of intuitive representation, such as the intuition of the continuum, of curves and planes, projections, and so on. Lorenzen's refusal to accept the classical, general concept of a real number means that complete arithmetization of real numbers is impossible. Indeed, such an arithmetization would require that the definition of each Dedekind cut be possible without referring to the quantity denoted by the cut. Of course, such an independent arithmetic definition of cuts is often possible: the length of the diagonal of the unit square, for example, is defined by the set of fractions whose squares are less than 2. However, we have no general proof that each cut is independently arithmetically definable (Bernays 1979, 6 ff). According to Bernays, such a strict arithmetization is by no means necessary, provided we introduce a set theory motivated by geometric intuition:

When the method of conventional analysis is accused of impredicativity, this is because, in the theory of the real numbers, one does not want to get involved with the kind of idealization which lies in envisaging the continuum as the "number line". ... Yet, if one conceives the real numbers as represented by definitory formulae for sets or for sequences of fractions (or of rational numbers), $\ldots$, then these - in this respect one must certainly agree with Lorenzen - form only an indefinite totality. But this is not suitable for representing the continuum.

The critics of classical analysis call for a more pronounced arithmetization of analysis. But it is possible to conceive of classical analysis in the sense of a closer fusion of geometry and arithmetic, which gives as good a unity of theory as a full arithmetization. (Bernays 1979, 14)

The question to be answered by Lorenzen is thus: "Can we conceive that the postulate of the power set of rational numbers is motivated by our geometric representation of the continuum?" (Lorenzen 1978, 222). This question seems 
insoluble as long as one maintains the classical understanding of geometry as a science of space (ibid., p. 224).

\section{References}

Becker, Oskar. 1956/57. Review of Paul Lorenzen: Einführung in die operative Logik und Mathematik. Kant-Studien 48:447-454.

Bernays, Paul. 1979. "Bemerkungen zu Lorenzens Stellungnahme in der Philosophie der Mathematik." In Konstruktionen versus Positionen: Beiträge zur Diskussion um die Konstruktive Wissenschaftstheorie (Paul Lorenzen zum 6o. Geburtstag), edited by K. Lorenz, volume I: Spezielle Wissenschaftstheorie, pages 3-16. Berlin/New York: De Gruyter.

Curry, Haskell B. 1951. Outlines of a formalist philosophy of mathematics. Amsterdam: North-Holland.

Dingler, Hugo. 1913. Die Grundlagen der Naturphilosophie. Leipzig: Verlag Unesma (Darmstadt: Wissenschaftliche Buchgesellschaft, 1967).

- 1931. Philosophie der Logik und Arithmetik. Munich: Ernst Reinhardt.

Feferman, Solomon. 1964. "Systems of predicative analysis." Journal of Symbolic Logic 29 (1): 1-30.

. 1979. "A more perspicuous formal system for predicativity." In Konstruktionen versus Positionen: Beiträge zur Diskussion um die Konstruktive Wissenschaftstheorie (Paul Lorenzen zum 6o. Geburtstag), edited by K. Lorenz, volume I: Spezielle Wissenschaftstheorie, pages 68-93. Berlin/ New York: De Gruyter.

Fontaine, Matthieu, and Juan Redmond. 2008. Logique dialogique: Une introduction. Cahiers de Logique et d'Epistémologie, volume 5. Milton Keynes: College Publications.

Gethmann, Carl Friedrich. 1991. Lebenswelt und Wissenschaft: Studien zum Verhältnis von Phänomenologie und Wissenschaftstheorie. Bonn: Bouvier.

Gethmann, Carl Friedrich, and Geo Siegwart. 1994. "The constructivism of the 'Erlanger Schule': Background, goals and developments." Cogito 8 (3): 226-233.

Heinzmann, Gerhard, and Jean Petitot. 2020. "The functional role of structures in Bourbaki." In The pre-history of mathematical structuralism, edited by E. H. Reck and G. Schiemer, pages 187-214. Oxford University Press.

Hölder, Otto. 1924. Die mathematische Methode: Logisch-erkenntnistheoretische Untersuchungen im Gebiete der Mathematik, Mechanik und Physik. Berlin: Springer.

Inhetveen, Rüdiger. 1983. Konstruktive Geometrie: Eine formentheoretische Begründung der euklidischen Geometrie. BI-Wissenschaftsverlag.

Janich, Peter. 1989. Euklids Erbe: Ist der Raum dreidimensional? München: Beck. (English translation by D. Zook: Euclid's heritage: Is space three- 
dimensional? Dordrecht: Springer, 1992.)

Keiff, Laurent. 2011. "Dialogical logic." In The Stanford encyclopedia of philosophy, edited by E. N. Zalta (Summer 2011 edn.). Metaphysics Research Lab, Stanford University. https://plato.stanford.edu/arc hives/sum2011/entries/logic-dialogical/

Lorenzen, Paul. 1950. "Konstruktive Begründung der Mathematik." Mathematische Zeitschrift 53:162-201.

_. ${ }^{1}$ 1955a. Einführung in die operative Logik und Mathematik. Berlin/ Heidelberg/New York: Springer; quoted according to the second edition 1969.

- 1955b. "Über eine Erweiterung des finiten methodischen Rahmens." In Actes $d u 2^{e}$ congrès international de l'Union Internationale de Philosophie des Sciences, Zürich 1954, volume II, pages 128-134. Neuchâtel.

. 1958. "Logical reflection and formalism." Journal of Symbolic Logic 23: 241-249.

. 1961. "Das Begründungsproblem der Geometrie als Wissenschaft der räumlichen Ordnung." Philosophia Naturalis 6:415-431; reprinted in Lorenzen 1969, 120-141.

- 1965. Differential und Integral: Eine konstruktive Einführung in die klassische Analysis. Frankfurt a. M.: Akademische Verlagsgesellschaft.

- 1968. "Constructive mathematics as a philosophical problem." In Logic and foundations of mathematics: Dedicated to Prof. A. Heyting on his 7oth birthday, edited by D. van Dalen, J. G. Dijkman, S. C. Kleene, and A. S. Troelstra, pages 133-142. Wolters-Noordhoff, Groningen. . 1969. Methodisches Denken. Frankfurt a. M.: Suhrkamp ( $\left.{ }^{1} 1968\right)$.

. 1978. "Konstruktive Analysis und das Geometrische Kontinuum." Dialectica 32:221-227.

- 1987. Lehrbuch der konstruktiven Wissenschaftstheorie. Mannheim/ Wien/Zürich: Wissenschaftsverlag.

—. 1994. "Konstruktivismus." Journal for General Philosophy of Science 25:125-133.

Lorenzen, Paul, and Wilhelm Kamlah. 1967. Logische Propädeutik: Eine Vorschule des vernünftigen Denkens. Mannheim: Bibliographisches Institut.

Lorenzen, Paul, and Kuno Lorenz. 1978. Dialogische Logik. Darmstadt: Wissenschaftliche Buchgesellschaft.

Mittelstraß, Jürgen. 2005-2017. Enzyklopüdie Philosophie und Wissenschaftstheorie. Second edition, eight volumes. Stuttgart/Weimar: J. B. Metzler.

— (ed.). 2008. Der Konstruktivismus in der Philosophie im Ausgang von Wilhelm Kamlah und Paul Lorenzen. Paderborn: Mentis.

- 2016. "Paul Lorenzen und die Erlanger Schule." In Paul Lorenzen und die konstruktive Philosophie, edited by J. Mittelstraß, pages 11-25. Münster: Mentis.

Parsons, Charles. 2002. "Realism and the debate on impredicativity, 19171944." In Reflections on the foundations of mathematics: Essays in honor of Solomon Feferman, edited by W. Sieg, R. Sommer, and C. Talcott, pages 
372-389. Association for Symbolic Logic.

Rahman, Shahid, Zoe McConaughey, Ansten Klev, and Nicolas Clerbout. 2018. Immanent reasoning or Equality in action: A plaidoyer for the play level, volume 18 of Logic, Argumentation \& Reasoning. Cham: Springer.

Schlaudt, Oliver. 2014. "La réception de Hugo Dingler par l'École d'Erlangen." Philosophia Scientix 18 (2): 141-159.

Schroeder-Heister, Peter. 2008. "Lorenzen's operative justification of intuitionistic logic." In One hundred years of intuitionism (1907-2007): The Cerisy conference, edited by M. van Atten, P. Boldini, M. Bordeau, and G. Heinzmann, pages 214-240. Basel/Boston/Berlin: Birkhäuser.

Thiel, Christian. 2014. "Phenomenology, 'Grundwissenschaft' and 'Ideologiekritik': Hermann Zeltner's critique of the Erlangen School." In Interdisciplinary works in logic, epistemology, psychology and linguistics: Dialogue, rationality, formalism, edited by M. Rebuschi, M. Batt, G. Heinzmann, F. Lihoreau, M. Musiol, and A. Trognon, pages 11-19. Springer.

Wang, Hao. 1954. "The formalization of mathematics." Journal of Symbolic Logic 19:241-266.

—. 1959. "Ordinal numbers and predicative set theory." Zeitschrift für mathematische Logik und Grundlagen der Mathematik 5:216-239.

- 1964. A survey of mathematical logic. Peking/Amsterdam: Science Press/North-Holland.

Weyl, Hermann. 1918. Das Kontinuum: Kritische Untersuchungen über die Grundlagen der Analysis. Chelsea/New York, no date (1918).

_. 1921. "Über die neue Grundlagenkrise der Mathematik." Mathematische Zeitschrift 10:39-79.

—. 1968. "Nachtrag Juni, 1955" [concerning Weyl 1921]. In his Gesammelte Werke, volume II, pages 179-180. Berlin/Heidelberg/New York: Springer.

. 1985. "Axiomatic versus constructive procedures in mathematics." Mathematical Intelligencer 7: 10-17, 38.

Open Access This chapter is licensed under the terms of the Creative Commons Attribution 4.0 International License (http://creativecommons.org/licenses/by/4.0/), which permits use, sharing, adaptation, distribution and reproduction in any medium or format, as long as you give appropriate credit to the original author(s) and the source, provide a link to the Creative Commons license and indicate if changes were made.

The images or other third party material in this chapter are included in the chapter's Creative Commons license, unless indicated otherwise in a credit line to the material. If material is not included in the chapter's Creative Commons license and your intended use is not permitted by statutory regulation or exceeds the permitted use, you will need to obtain permission directly from the copyright holder. 